\title{
The Relationship of Personality, Spirituality and Posttraumatic Growth to Subjective Wellbeing
}

\author{
Michael Galea \\ University of Malta, Msida, Malta \\ Email: mgalea00@yahoo.com
}

Received 26 August 2014; revised 3 October 2014; accepted 5 November 2014

Copyright (C) 2014 by author and OALib.

This work is licensed under the Creative Commons Attribution International License (CC BY). http://creativecommons.org/licenses/by/4.0/

(c) (i) Open Access

\begin{abstract}
A growing number of studies are indicating that a number of people report psychological growth after experiencing trauma. This may be so because suffering stimulates the need and search for meaning [1]. In this cross-sectional and correlational study, we sought the relationship of subjective wellbeing to posttraumatic growth in view of past trauma experiences and perceived stress. In particular, we investigated a sample of tertiary students' perceived stress, past traumas, subjective well-being, faith maturity, positive and negative affect, and personality, together with demographic correlates. Past traumas included loss of a loved one, chronic or acute illness, injury, divorce, violent crime, and job loss, amongst others. Only a quarter of respondents experienced their trauma/s 5 years or more prior the study, thus indicating relatively recent trauma experiences. Post-traumatic growth correlated with personality, faith maturity, wellbeing and positive affect. In examining the patterns of correlations noted above, a hierarchical multiple regression analysis was employed. Posttraumatic growth was found to have unique variance even after partialling out key variables such as perceived stress, personality and faith maturity. Although situational factors and personality did play important roles, this study clearly points at the relevance of faith maturity and posttraumatic growth for the promotion of holistic wellbeing of those affected by trauma. Religious beliefs may counter hopelessness and form an important buffer in this equation. The psycho-social implications of these results were discussed.
\end{abstract}

\section{Keywords}

Posttraumatic Growth, Spirituality, Wellbeing, Trauma, Stress

Subject Areas: Education, Psychology, Sociology

\section{Introduction}

People are resilient, much more than we usually think. However, despite one's own resourcefulness and expe-

How to cite this paper: Galea, M. (2014) The Relationship of Personality, Spirituality and Posttraumatic Growth to Subjective Wellbeing. Open Access Library Journal, 1: e1069. http://dx.doi.org/10.4236/oalib.1101069 
riences, the truth remains that each individual has his or her own breaking point. In effect, psychological wellbeing and holistic health lies somewhere between these two extremes, along the same continuum.

A growing number of studies are indicating that people report psychological growth after experiencing trauma. Studies, mostly influenced by the positive psychology movement, explored this phenomenon. This was nicknamed posttraumatic growth [2], and stress-related growth [3], amongst others. Cann, Calhoun, Tedeschi, and Lindstrom [4] suggested that challenge to core beliefs was the main predictor of posttraumatic growth (PTG), and that a very large proportion of the sample in their study had encountered themes of PTG in their sociocultural contexts. Individuals confronted with a life-threatening illness often report posttraumatic growth or finding benefits in disease.

However, at least two controversies erupted surrounding this issue: whether PTG reflects true positive changes, and whether what is measured is truly growth (dubbed the validity controversy).

Kunst [5] suggested that peritraumatic distress enables growth after substantial time has elapsed since victimization. Luszczynska, Durawa, Dudzinska, Kwiatkowska, Knysz and Knoll [6] have also emphasized the defensive character of PTG, that is finding benefits in illness and changes in the function of these beliefs over time elapsing since diagnoses.

Kleim and Ehlers [7] found that PTG may be most relevant in trauma survivors who attach enduring significance to the trauma for their lives and show initial distress. Moderate levels of PTG do not seem to ameliorate post trauma psychopathology.

Kira, Abourmediene, Ashby, Odenat, Mohanesh, and Alamia [8] indicated that PTG was not a significant predictor of any mental health symptoms and that PTG is different from growth in non-traumatic situations. The results suggest that it is important to analyze trauma profiles rather than single trauma.

Evans [9] found a high incidence of trauma among graduate students and low to moderate amounts of growth following trauma in $29 \%$ of the respondents. There does appear to be a relationship between having experienced trauma and achieving growth, specifically where the trauma experienced was of a horrific, shocking, and grotesque nature and relating to a total growth measure. What kinds of trauma are related to more specific kinds of growth was not made clear, however.

Taku, Kilmer, Cann, Tedeschi, and Calhoun [10] suggested that the youth-reported growth does not simply reflect normative maturation. Multiple regression analysis, using participants who reported at least one traumatic event, indicated that deliberate cognitive processing appears to play an important role in PTG. Cultural and developmental aspects of these findings, as well as implications for research and applied work are discussed.

As indicated by Haidt [11], empirical research seems to agree on three key potential benefits of posttraumatic growth, namely: 1) feeling stronger and finding hidden abilities and inner strengths; 2) the strengthening of good relationships; and 3) the alteration of priorities and philosophies concerning the present day (appreciating more the present) and other people (prioritizing significant others in our life).

However, literature is mixed when it tries to explain the link between PTG and subjective wellbeing. Park and Helgeson [12] found negative association or no association at all. More clarification work is thus required. For example, it is still debatable whether posttraumatic growth should be seen as a process or as an outcome variable.

Thus, Helgeson, Reynolds, and Tomich [13] proposed three main hypotheses: first, that PTG leads to positive life changes which improve wellbeing; second, that PTG does lead to life changes but comes at the price of lowering wellbeing because it is a stressful journey, and finally, that PTG is a coping strategy which mediates the relationship between trauma and wellbeing.

Moreover, researchers are still unclear whether posttraumatic growth is a kind of resilience, or rather resilience plays a key role in the development of PTG. Bonanno and Mancini [14] explained resilience as an adaptive process that occurs in the wake of trauma, to be able to maintain a healthy psychological wellbeing. On the other hand, Tedeschi and McNally [15] indicated an inverse relationship between PTG and resilience, where highly resilient people experienced less PTG than less resilient people.

The intriguing question is why some individuals experience more posttraumatic growth than others. Empirical research has consistently found that personality traits and mood states have significantly been linked to PTG [16] [17]. Such variables may have a unique contribution to how a person manages to interpret life's traumas, despite the suffering and challenges inherent in them [18].

In this study, personality variables were entered into the equation, considering the close affinity that personality traits have to post-traumatic growth. 
To conclude, therefore, key issues highlighted in the ever-increasing PTG empirical literature include: the still controversial definition of growth after trauma, what does PTG refers to, its exact relationship to wellbeing, and potential key factors that facilitate PTG's development.

For the purpose of this study, we hypothesized that subjective wellbeing will correlate with personality, spirituality and posttraumatic growth, in view of past perceived traumatic experiences and stress. Moreover, we also hypothesized that more significantly, spirituality and posttraumatic growth would both have unique variance in predicting subjective wellbeing among a sample of tertiary students with past trauma experiences, over and above the contribution of personality and other key variables.

\section{Method}

\subsection{Participants}

Participants (28\% male, 72\% female) were 194 University of Malta students. Subjects varied in age according to the following ranges: 18 - $32(M=21.60, S D=6.51)$. Participants were predominantly Maltese citizens (89\%). As was expected, the majority are still single (85\%), while the rest are either married or in a relationship. Moreover, $81 \%$ indicated to being Catholic, $2 \%$ Protestant, $4 \%$ Jewish, while $13 \%$ indicated no religious affiliation. A little over half the sample expressed themselves as committed to their respective faith.

\subsection{Materials}

Posttraumatic growth. The Posttraumatic Growth Inventory (PTGI) was developed by Tedeschi and Calhoun [2] to assess any positive outcomes in people in view of traumatic occurrences. The PTGI is a 21-item inventory measure that tries to capture five domains or factors of growth, namely: one's relating to others, new possibilities, personal strength, spiritual change, and a deeper appreciation of life. Items are rated on a 0 (I did not experience this change) to 5 (I experienced this change to a great degree) scale. Scores range from 0 to 105 . The scale has acceptable test-retest reliability [2]. The short form (10 items) was used in this study ( $\mathrm{M}=32.27, \mathrm{SD}=$ 7.70). Alpha coefficient was found to be 0.83 .

Posttraumatic Stress Disorder (PTSD) symptoms. The PTSD Checklist, Civilian Version (PCL-C) was developed by Frank Weathers and his colleagues at the United States National Center for PTSD [19]. It is a 17-item self-report measure reflecting DSM-IV symptoms and criteria of PTSD. An alpha of 0.94 and an overall correlation between total PCL-C and the Clinician-Administered PTSD Scale (CAPS) scores was found at 0.93 [20]. $(M=42.83, S D=13.94)$. Alpha coefficient for this sample was 0.70 .

Personality. Personality was assessed through the International Personality Item Pool (IPIP), short version, developed by Goldberg [21]. The IPIP represents the NEO PI R. It is based on the Big-Five factor structure, namely: extraversion (tendency to experience positive emotions), agreeableness (tendency of be cooperative and agreeable in human relations), conscientiousness (degree to which a person is disposed to be dutiful to one's role and obligations), emotional stability (tendency to experience positive emotions) and openness to experience (interest in a variety of internal and external experiences). Alpha coefficients for this study were found at $0.75,0.70$, $0.78,0.80$, and 0.66 respectively. The IPIP is scored on a 5-point Likert-type scale ranging from 1 (false) to 5 (always true). The full IPIP contains 300 items. It estimates a person's standing on the 5-broad domains and 30 sub domains of personality.

Stress. The Perceived Stress Scale (PSS) is a 4-item scale developed by Cohen, Kararck and Mermelstein [22] as a global measure of perceived stress. Items are rated on a 0 (never) to 4 (very often). It was designed for use with community samples. Items include "in the last month, how often have you felt that you were unable to control the important things in your life?" and "in the last month, how often have you felt that things were going your way?” ( $\mathrm{M}=8.03, \mathrm{SD}=2.54, \alpha=0.80)$.

Wellbeing. Subjective wellbeing was assessed by the Satisfaction with Life Scale (SWLS), developed by Diener, Emmons, Larsen and Griffin [23]. It is a short 5-item instrument designed to measure global cognitive judgments of satisfaction with one's life. The authors believe that there is no one element to life satisfaction, but rather a recipe that includes a number of ingredients. Factors included in this short scale are: social relationships, work/school dynamics, personal satisfaction with self, spiritual life, growth and leisure. The authors indicated an alpha coefficient of 0.80 . The alpha in this study was $0.82(\mathrm{M}=47.94, \mathrm{SD}=9.97)$.

Spirituality. The Faith Maturity Scale (FMS), developed by Benson, Donahue and Erickson [24], has two 
subgroups: faith maturity vertical (FMV) and faith maturity horizontal (FMH). The measure has good internal reliability (alpha coefficient 0.88 ). This scale measures the extent that participants seek spiritual growth. The FMS was selected for two reasons. First, its psychometric properties appear to be very acceptable. Secondly, it encompasses two main tenets of what spirituality to our knowledge must entail: love of the transcendent being or God and love of neighbor. At the core of the FMS is an understanding of faith as having "vertical" (inward journey, relationship to God), and "horizontal" (outward journey, relationship to others) dimensions, with an integration of both resulting in faith maturity. The authors described the measure as having a holistic sense focus, namely: integration of faith and life, holding life-affirming values, advocating social change, action and service [25]. The alpha reliability for the Faith Maturity Scale in this study was $0.90(M=54.03, S D=13.93)$.

Positive \& Negative Affect. The Positive and Negative Affect Schedule (PANAS), was developed by Watson, Clark, and Tellegen [26]. It is a 20-item scale comprises of two mood scales, measuring positive and negative affect. Each item is rated on a 5-point Likert scale $(1=$ not at all, to $5=$ extremely) to indicate the extent to which the respondent has felt this way in the indicated time frame. The authors report Cronbach's alpha coefficients ranging from 0.86 to 0.90 for the Positive Affect scale and a range of 0.84 to 0.87 for the Negative Affect scale. Test-retest correlations for a two-month period ranged from 0.47 to 0.68 for Positive Affect, and 0.39 to 0.71 for Negative Affect. Average alpha coefficient for this study was 0.72 for Positive Affect $(\mathrm{M}=31.24$, SD = 6.93) and 0.74 for Negative Affect $(M=19.56, S D=7.08)$.

\subsection{Procedure}

After getting all ethical approval for this research, the questionnaire and a cover letter were sent by the University of Malta to a randomly-selected pool of students who upon entry as tertiary students, indicated their willingness to partake in such studies. In total, 300 invitations were sent out. Inclusion criteria included students at the University of Malta who were presently enrolled in undergraduate degree.

Potential participants were contacted by e-mail by the University of Malta. In total, 194 students responded, with a response rate of $65 \%$. The e-mail included a cover letter signed by the researcher, explaining the main tenets of the study, together with a link to the questionnaire. Students could participate only once in the study. A code was assigned to every completed questionnaire that was returned, and then forwarded to the researcher. The researcher had no knowledge of the identity of participants, nor of their e-mail information. The study was on a voluntary and confidential basis. It was conducted during the first half of 2013. Participants had one week to respond.

\section{Results}

A total of 194 tertiary students participated in this study. Results indicated that $42 \%$ experienced the loss of a loved one, $9 \%$ had a chronic or acute illness, an accident or injury; $7 \%$ a change in family responsibility; $6 \%$ a career or location move; $5 \%$ went through divorce; $2 \%$ experienced a violent or abusive crime, or disaster; $1 \%$ a job loss or financial hardship; and 16\% indicated some other type of trauma which they did not want to identify. Around 28\% of respondents experienced the event within one year prior the study, 25\% of respondents experienced the traumatic event from 1 to 2 years prior, 20\% of students from 2 to 5 years, while the rest (27\%) experienced trauma more than 5 years prior. Table 1 shows the correlation matrix of the key variables used.

Faith maturity correlated positively with subjective wellbeing ( $1194, \mathrm{t}=0.33, p<0.01$ ), with positive affect (r194, $\mathrm{t}=0.43, p<0.001$, agreeableness ( $\mathrm{r} 194, \mathrm{t}=0.26, p<0.05$ ), and also with posttraumatic growth ( $\mathrm{r} 194, \mathrm{t}=$ $0.64, p<0.001$ ). Research has established a consistent relationship between important life events and one's tendency toward transcendence or spirituality [28].

Wellbeing correlated with positive affect ( $\mathrm{r} 194, \mathrm{t}=0.50, p<0.001$ ), posttraumatic growth ( $\mathrm{r} 194, \mathrm{t}=0.43, p<$ 0.001 ), negative affect ( $\mathrm{r} 194, \mathrm{t}=-0.26, p<0.01$ ), perceived stress ( $\mathrm{r} 194, \mathrm{t}=-0.43, p<0.001)$. Wellbeing also correlated negatively with posttraumatic stress disorder ( $\mathrm{r} 194, \mathrm{t}=-0.32, p<0.01)$.

Extraversion correlated positively with all the personality domains and also with perceived stress $(\mathrm{r} 194, \mathrm{t}=$ $-0.24, p<0.05)$.

Besides the above correlations, posttraumatic stress disorder correlated also with negative affect $(\mathrm{r} 194, \mathrm{t}=$ $0.36, p<0.001$ ), and perceived stress ( $\mathrm{r} 194, \mathrm{t}=0.39, p<0.001$ ).

Posttraumatic growth correlated with positive affect ( $\mathrm{r} 194, \mathrm{t}=0.47, p<0.001)$, agreeableness ( $\mathrm{r} 194, \mathrm{t}=0.27$, $p<0.01$ ), and with conscientiousness ( $\mathrm{r} 194, \mathrm{t}=0.27, p<0.01)$. 
Table 1. Descriptive statistics and correlation matrix of key variables.

\begin{tabular}{|c|c|c|c|c|c|c|c|c|c|c|c|c|}
\hline & 1 & 2 & 3 & 4 & 5 & 6 & 7 & 8 & 9 & 10 & 11 & 12 \\
\hline 1. SP & - & & & & & & & & & & & \\
\hline 2. WB & $0.33^{* *}$ & - & & & & & & & & & & \\
\hline 3. PA & $0.43^{* * * *}$ & $0.50^{* * *}$ & - & & & & & & & & & \\
\hline 4. NA & 0.08 & $-0.26^{* *}$ & -0.17 & - & & & & & & & & \\
\hline 5. PS & -0.05 & $-0.43^{* * *}$ & -0.16 & $0.41^{* * * *}$ & - & & & & & & & \\
\hline 6. EX & -0.00 & 0.08 & 0.12 & 0.05 & $-0.24^{*}$ & - & & & & & & \\
\hline 7. AG & $0.26^{*}$ & 0.06 & $0.26^{*}$ & 0.07 & -0.01 & $0.46^{* * *}$ & - & & & & & \\
\hline 8. $\mathrm{CN}$ & 0.17 & 0.12 & $0.35^{* *}$ & -0.11 & -0.19 & 0.22 & $0.28^{*}$ & - & & & & \\
\hline 9. NR & 0.06 & -0.06 & 0.03 & 0.03 & -0.07 & $-0.36^{* * *}$ & $-0.27^{* *}$ & $-0.29^{* *}$ & - & & & \\
\hline 10. OP & 0.16 & -0.12 & 0.12 & 0.10 & 0.13 & $0.24^{*}$ & $0.36^{* * *}$ & $0.45^{* * *}$ & $0.25^{*}$ & - & & \\
\hline 11. PT & $0.64^{* * *}$ & $0.43^{* * *}$ & $0.47^{* * *}$ & 0.01 & -0.05 & 0.17 & $0.27^{* *}$ & $0.27^{* *}$ & -0.02 & 0.07 & - & \\
\hline 12. PTS & 0.07 & $-0.32^{* *}$ & 0.02 & $-0.36^{* * *}$ & $0.39^{* * *}$ & -0.08 & 0.09 & -0.14 & 0.06 & 0.18 & -0.06 & - \\
\hline
\end{tabular}

Note: $N=194 .{ }^{*} p<0.05 ;{ }^{* *} p<0.01 ;{ }^{* * *} p<0.001$. SP = Faith Maturity Scales; WB = Subjective Wellbeing; PA = Positive Affect; NA = Negative Affect; PS = Perceived Stress Scale; EX = Extraversion; AG = Agreeableness; CN = Conscientiousness; $\mathrm{NR}=$ Neuroticism; OP = Openness; PT = Posttraumatic Growth; PTS = Post Traumatic Stress Disorder.

Table 2 shows the results of the multiple hierarchical regressions in predicting all or any of the components of subjective wellbeing.

We hypothesized that spirituality and posttraumatic growth would both have significant unique variance in predicting subjective wellbeing among a sample of tertiary students with past trauma experiences.

To determine this possibility, a series of hierarchical regressions were performed for all predictor variables with all components of subjective wellbeing entered separately as the criterion variable. Table 2 presents the results for these hierarchical regressions.

It was hypothesized that posttraumatic growth and spirituality would have unique variance in predicting subjective wellbeing over and above the contribution of personality and perceived stress. To determine this possibility, a series of hierarchical regressions were performed for all predictor variables with each subjective wellbeing criterion variable, namely: positive affect, negative affect and cognitive wellbeing.

Perceived stress (PSS) was entered in the first step in the regression analysis. PSS was only a significant predictor of negative affect.

In the second step, personality variables were entered in a block. Personality was a significant predictor of positive affect and subjective wellbeing, making a contribution between $11 \%$ to $17 \%$, over and above perceived stress. Neuroticism $(\beta=-0.13, p<0.05)$ and conscientiousness $(\beta=0.35, p<0.01)$ were both significant predictors of wellbeing.

Faith maturity was entered in the third step, and predicted significantly positive affect and subjective wellbeing, with a range from $24 \%$ to $26 \%$, over and above perceived stress and personality.

Posttraumatic growth was entered in the final step. As can be seen in Table 2, faith maturity did account for additional variance in predicting wellbeing in a range from $18 \%$ to $33 \%$. In particular, PTG predicted all wellbeing scales. This was achieved even after controlling for perceived stress, personality, and faith maturity.

The beta weights in Table 3 further clarify the relationship between the predictor variables and the subjective wellbeing variants. Conscientiousness and Neuroticism carried the bulk of the predictive variance for the personality variables. The beta weights also confirmed that faith maturity positively relates to positive affect and cognitive wellbeing, but not to negative affect. As is expected, posttraumatic growth relates to all facets of subjective wellbeing.

\section{Discussion}

Results clearly indicate that faith maturity related positively with wellbeing, positive affect, personality and posttraumatic growth, thus suggesting that it relates well with important life events.

Posttraumatic growth positively correlated with a personality profile that is high on conscientiousness and 
Table 2. Hierarchical multiple regression predicting subjective wellbeing.

\begin{tabular}{ccccc}
\hline & Model & $R^{2}$ & $\Delta R^{2}$ & $F$ Change \\
\hline Positive Affect & & & & 9.025 \\
Step 1 & PSS & 0.21 & 0.17 & $12.605^{* * *}$ \\
Step 2 & Personality & 0.12 & 0.11 & $15.964^{* * *}$ \\
Step 3 & Faith Maturity & 0.26 & 0.24 & $13.104^{* *}$ \\
Step 4 & PTG & 0.30 & 0.28 & $18.329^{* *}$ \\
Negative Affect & & & 12.964 \\
Step 1 & PSS & 0.16 & 0.15 & 12.281 \\
Step 2 & Personality & 0.12 & 0.10 & $8.161^{*}$ \\
Step 3 & Faith Maturity & 0.21 & 0.19 & 0.234 \\
Step 4 & PTG & 0.21 & 0.18 & $20.183^{* *}$ \\
Cognitive wellbeing & & & & $17.144^{* *}$ \\
Step 1 & PSS & 0.10 & 0.15 & $16.334^{* *}$ \\
Step 2 & Personality & 0.18 & 0.17 & 0.26 \\
Step 3 & Faith Maturity & 0.27 & 0.33 & \\
Step 4 & PTG & 0.35 & & \\
\hline
\end{tabular}

Note: $N=194 .{ }^{*} p<0.05 ;{ }^{* *} p<0.01 ;{ }^{* * *} p<0.001$. PSS = Perceived Stress; PTG = Posttraumatic Growth.

Table 3. Beta weights for predictors of subjective wellbeing.

\begin{tabular}{cccc}
\hline Predictor & PosAf & NegAf & Cognitive Wellbeing \\
\hline Neuroticism & $-0.13^{*}$ & $0.27^{*}$ & $-0.01^{*}$ \\
Extroversion & 0.22 & 0.11 & 0.17 \\
Openness & -0.01 & 0.01 & 0.17 \\
Agreeableness & 0.32 & -0.21 & 0.02 \\
Conscientiousness & $0.35^{* *}$ & 0.21 & $0.07^{*}$ \\
PSS & -0.03 & $0.41^{* *}$ & $-0.43^{* * *}$ \\
Faith maturity & $0.38^{*}$ & 0.00 & $0.38^{*}$ \\
PTG & $0.28^{* *}$ & $0.04^{*}$ & $0.36^{* *}$ \\
\hline
\end{tabular}

Note: $N=194 .{ }^{*} p<0.05 ;{ }^{* *} p<0.01 ;{ }^{* * *} p<0.001$. PosAf = Positive Affect, NegAf = Negative Affect, PSS = Perceived Stress, PTG = Posttraumatic Growth.

agreeableness. A conscientious individual is guided by an inner sense of what is "right". Such individuals typically share reputations for being meticulous, thorough and deliberate. Two aspects of conscientiousness are industriousness and orderliness. A profile high on agreeableness indicates altruism, trust and pro-social attitudes. Compassion and politeness are two aspects of agreeableness. Empathy, or genuine outlook, seems to be the key feature of such a personality. Adding this characteristic together with conscientiousness, the result would be a personality profile that shares positive correlations with the aspects of integrity. In sum, therefore, posttraumatic growth suggests a personality high on empathy and orderliness.

The third hypothesis was also supported. PTG and faith maturity both had unique variance in predicting wellbeing, even after partialling out the contribution of personality and perceived stress.

Perceived stress was significantly related to negative affect, as is expected, but not to positive affect or cognitive wellbeing. Interestingly, faith maturity contributed almost twice as much variance as personality to positive affect and cognitive wellbeing. This continues to support research on the unique predictiveness of spirituality to wellbeing in view of trauma and perceived stress. On the other hand, faith maturity was not found related to negative affect.

PTG was related to all components of wellbeing. This variable predicts a plethora of feelings, and affects the individual in diverse ways, not just in producing a meaningful sense, but may also come at the price of scars 
from past emotional trauma. PTG explained from 18\% to 33\% of the variance for the separate subjective wellbeing components, after controlling for perceived stress, personality and faith maturity.

Three points of comparison need to be made. First, these results were found even after partialing out key relevant variables, thus this truly reflects the unique predictiveness of spirituality and posttraumatic growth to holistic wellbeing.

Second, it is interesting to note that the single dimension of faith maturity adds almost twice as much as the personality scales bundled together. Results showing the unique predictiveness of spirituality over and above personality were also found in other studies [27] [28].

Finally, the goal of multiple regression analysis is to find the contributions of all relevant variables, not simply the strongest variables. The aim is to provide the most comprehensive explanatory model possible.

The value of spirituality to wellbeing has been shown specifically in three perspectives: as a coping mechanism against negative life events, as a social support, and as providing meaningfulness in life [29]-[33]. That spirituality is different from subjective wellbeing is clear. However, they do seem to complement each other. For example, one who experiences subjective wellbeing might per result to this consider spiritual matters and be driven in life by those values. Research has shown strong correlation between them.

Galea found that transcendence or spirituality correlated significantly with subjective wellbeing and positive affect [34] [35]. However, no direct relation with negative affect was found. This is consistent with this study's results as well.

This may suggest that although spirituality may not be directly linked to a decrease of pain, it may have a unique impact in providing a framework through which painful experiences may be more easily borne [36]-[38]. Thus, spirituality seems to help in the increase of inner joy despite the difficulties of life.

This phenomenon may indicate that part of transcendence may act counter-intuitively. Many of the conceptual and practical approaches to spirituality have seen its role in terms of coping with psychological pain and trauma. Ironically, multiple studies now show that, when controlling for personality, spirituality has minimal ability to reduce negative effects [39] [40]. These results suggest that positive psychology would do well to continue its interest in spirituality and transcendence as key character strengths [41]. Far from being a human quality that speaks only to the dark side of human nature and existence, the real value of spirituality from a functional psychological standpoint may well be its ability to enhance human flourishing.

Results suggest that a healthy spirituality is a resource and is highly correlated to emotional wellbeing. Consistent with this finding, researchers [42]-[44], viewed spirituality as an important construct for wellbeing, particularly in countering traumatic ordeals in life. Some studies have found that whenever spirituality was factored in, it was always found significantly related to healthy outcomes, and inversely related to disorders [45]. In line with this, some results [46] [47] found that spirituality predicted a greater sense of wellbeing among abuse victims. If some trauma victims find inner peace through spirituality, then they would adhere to a more refined and personal spiritual journey, one that could enhance their healing.

How exactly spirituality works as a buffer is not clearly established. However, indications point at religious belief, rather than behavior, as being beneficial in providing a cognitive framework that might counter hopelessness [48]. Spirituality may ease the negative impact of trauma, by increasing affective wellbeing among individuals hurt somehow by a history of trauma. Baumeister [1] notes that "suffering stimulates the need for meaning” because "people analyze and questions their sufferings far more than their joys" (p.232).

\section{Limitations}

Because this study is basically correlational in nature, no inference of causality can be made. Moreover, the study's reliance upon self-reported and recalled data may have introduced sources of error. Individuals' responses may have become distorted over time. Another aspect is the cultural diversity, which may have a bearing on how individuals respond to trauma events in their past. This aspect may need to be factored in future studies.

Despite these limitations, however, this study's strengths are noteworthy. The exploratory nature of the impact of posttraumatic growth among Maltese tertiary students is an important aspect. Posttraumatic growth is increasing gaining attention even among cross-cultural populations, which adds to the increasing empirical research attesting to its value in view of past trauma. Another feature of this study was its multidimensional focus in bundling together measures of personality and psycho-spiritual wellbeing, singly identified as important in related research [17] [49] [50]. Their simultaneous application here allowed for a more sophisticated analysis of 
posttraumatic growth among trauma survivors.

The present study also confirms the incremental validity of faith maturity and posttraumatic growth, as predictors of the three subjective wellbeing components even when controlling for key variables. In particular, faith maturity and posttraumatic growth were robust variables and hold their own in explaining their relevance to holistic wellbeing. Faith maturity explained twice as much variance as personality. Moreover, posttraumatic growth predicted wellbeing even after controlling for personality, perceived stress, and faith maturity.

Although situational factors and personality did play important roles, this study clearly has indicated that spirituality and posttraumatic growth were also found to be important additional components of subjective wellbeing.

Religious beliefs may counter hopelessness and form an important part of this equation. Faith maturity may ease the negative impact of trauma, by increasing affective wellbeing and producing a wider perspective through which painful past traumas may somehow be more easily envisaged.

\section{References}

[1] Baumeister, R.F. (1991) Meanings of Life. Guilford, New York.

[2] Tedeschi, R.G. and Calhoun, L. (1998) Posttraumatic Growth: Future Directions. In: Tedeschi, R.G., Park, C.L. and Calhoun, L.G., Eds., Post-Traumatic Growth: Positive Changes in the Aftermath of Crisis, Lawrence Erlbaum, Mahwah, 93-102.

[3] Park, C.L., Cohen, L.H. and Murch, R.L. (1996) Assessment and Prediction of Stress-Related Growth. Journal of Personality, 64, 71-105. http://dx.doi.org/10.1111/j.1467-6494.1996.tb00815.x

[4] Cann, A., Calhoun, L.G., Tedeschi, R.G. and Lindstrom, C.M. (2013) The Relationship of Core Belief Challenge, Rumination, Disclosure, and Sociocultural Elements to Posttraumatic Growth. Psychological Trauma: Theory, Research, Practice, and Policy, 5, 50-55. http://dx.doi.org/10.1037/a0022030

[5] Kunst, M.J.J. (2010) Peritraumatic Distress, Posttraumatic Stress Disorder Symptoms, and Posttraumatic Growth in Victims of Violence. Journal of Traumatic Stress, 23, 514-518. http://dx.doi.org/10.1002/jts.20556

[6] Luszczynska, A., Durawa, A.B., Dudzinska, M., Kwiatkowska, M., Knysz, B. and Knoll, N. (2012) The Effects of Mortality Reminders on Posttraumatic Growth and Finding Benefits among Patients with Life-Threatening Illness and Their Caregivers. Psychology \& Health, 27, 1227-1243. http://dx.doi.org/10.1080/08870446.2012.665055

[7] Kleim, B. and Ehlers, A. (2009) Evidence for a Curvilinear Relationship between Posttraumatic Growth and Posttrauma Depression and PTSD in Assault Survivors. Journal of Traumatic Stress, 22, 45-52. http://dx.doi.org/10.1002/jts.20378

[8] Kira, I.A., Aboumediene, S., Ashby, J.S., Odenat, L., Mohanesh, H. and Alamia, H. (2013) The Dynamics of Posttraumatic Growth across Different Trauma Types in a Palestinian Sample. Journal of Loss \& Trauma, 18, 120-139. http://dx.doi.org/10.1080/15325024.2012.679129

[9] Evans, J.H. (1997) Trauma and Posttraumatic Growth among Graduate Level Counselor Education Students: What Is Their Relative Incidence and What Relationships Do They Share? Dissertation Abstracts International Section A: Humanities \& Social Sciences, 58, 1600.

[10] Taku, K., Kilmer, R.P., Cann, A., Tedeschi, R.G. and Calhoun, L.G. (2012) Exploring Posttraumtic Growth in Japanese Youth. Psychological Trauma: Theory, Research, Practice, and Policy, 4, 411-419. http://dx.doi.org/10.1037/a0024363

[11] Haidt, J. (2006) The Happiness Hypothesis: Putting Ancient Wisdom and Philosophy to the Test of Modern Science. Arrow Books, London.

[12] Park, C.L. and Helgeson, V.S. (2006) Introduction to the Special Section: Growth Following Highly Stressful Life Events-Current Status and Future Directions. Journal of Consulting and Clinical Psychology, 74, 791-796. http://dx.doi.org/10.1037/0022-006X.74.5.791

[13] Helgeson, V.S., Reynolds, K.A. and Tomich, P.L. (2006) A Meta-Analytic Review of Benefit Finding and Growth. Journal of Consulting and Clinical Psychology, 74, 797-816. http://dx.doi.org/10.1037/0022-006X.74.5.797

[14] Bonanno, G.A. and Mancini, A.D. (2012) Beyond Resilience and PTSD: Mapping the Heterogeneity of Responses to Potential Trauma. Psychological Trauma: Theory, Research, Practice, and Policy, 4, 74-83. http://dx.doi.org/10.1037/a0017829

[15] Tedeschi, R.G. and McNally, R.J. (2011) Can We Facilitate Posttraumatic Growth in Combat Veterans? American Psychologist, 66, 19-24. http://dx.doi.org/10.1037/a0021896

[16] Stanton, A.L. and Low, C. (2004) Toward Understanding Posttraumatic Growth: Commentary on Tedeschi and Calhoun. Psychological Inquiry, 15, 76-80. 
[17] Costa, P.T. and McCrae, R.R. (1992) Normal Personality Assessment in Clinical Practice: The NEO Personality Inventory. Psychological Assessment, 4, 5-13. http://dx.doi.org/10.1037/1040-3590.4.1.5

[18] Tedeschi, R.G. and Calhoun, L.G. (2004) The Foundations of Posttraumatic Growth: New Considerations. Psychological Inquiry, 15, 1-18.

[19] Tedeschi, R.G. and Calhoun, L.G. (1996) The Posttraumatic Growth Inventory: Measuring the Positive Legacy of Trauma. Journal of Traumatic Stress, 9, 455-471. http://dx.doi.org/10.1002/jts.2490090305

[20] Weathers, F.W., Litz, B.T., Steinberg, H.R., Huska, J.A., Keane, T.M. and Orsillo, S.M. (1996) Current and Lifetime Psychiatric Disorders among Veterans with War Zone-Related Posttraumatic Stress Disorder. Journal of Nervous \& Mental Disease, 184, 307-313. http://dx.doi.org/10.1097/00005053-199605000-00007

[21] Blanchard, E.B., Alexander, E.J., Buckley, T. and Forneris, C. (2002) Emergency Room Vital Signs and PTSD in a Treatment Seeking Sample of Motor Vehicle Accident Survivors. Journal of Traumatic Stress, 15, 199-205. http://dx.doi.org/10.1023/A:1015299126858

[22] Goldberg, L.R. (1992) The Development of Markers for the Big-Five Factor Structure. Psychological Assessment, 4, 26-42. http://dx.doi.org/10.1037/1040-3590.4.1.26

[23] Cohen, S., Kamarck, T. and Mermelstein, R. (1983) A Global Measure of Perceived Stress. Journal of Health and Social Behavior, 24, 385-396. http://dx.doi.org/10.2307/2136404

[24] Diener, E., Emmons, R.A., Larsen, R.J. and Griffin, S. (1985) The Satisfaction with Life Scale. Journal of Personality Assessment, 49, 71-75. http://dx.doi.org/10.1207/s15327752jpa4901_13

[25] Benson, P.L., Donahue, M.J. and Erickson, J.A. (1993) The Faith Maturity Scale: Conceptualization, Measurement and Empirical Validation. Research in the Social Scientific Study of Religion, 5, 1-26.

[26] Watson, D., Clark, L.A. and Tellegen, A. (1988) Development and Validation of Brief Measures of Positive and Negative Affect: The PANAS Scales. Journal of Personality and Social Psychology, 54, 1063-1070. http://dx.doi.org/10.1037/0022-3514.54.6.1063

[27] Young, J.S., Cashwell, C.S. and Shcherbakova, J. (2000) The Moderating Relationship of Spirituality on Negative Life Events and Psychological Adjustment. Counseling \& Values, 45, 49-57. http://dx.doi.org/10.1002/j.2161-007X.2000.tb00182.x

[28] Golden, J., Piedmont, R.L., Ciarrocchi, J.W. and Rodgerson, T. (2004) Spirituality and Burnout: An Incremental Validity Study. Journal of Psychology \& Theology, 32, 115-125.

[29] Ellison, C.G. (1991) Religious Involvement and Subjective Well-Being. Journal of Health and Social Behavior, 32, 80-99. http://dx.doi.org/10.2307/2136801

[30] Marrone, R. (1999) Dying, Mourning and Spirituality: A Psychological Perspective. Death Studies, 23, 495-519. http://dx.doi.org/10.1080/074811899200858

[31] Galea, M., Ciarrocchi, J.W., Piedmont, R.L. and Wicks, R.J. (2007) Child Abuse, Personality, and Spirituality as Predictors of Happiness in Maltese College Students. Research in the Social Scientific Study of Religion, 18, 141-154. http://dx.doi.org/10.1163/ej.9789004158511.i-301.57

[32] Galea, M. (2008) The Impact of Child Abuse on the Psycho-Spiritual and Religious Status of Maltese College Students. Pastoral Psychology, 57, 147-159. http://dx.doi.org/10.1007/s11089-008-0159-5

[33] Galea, M. (2009) Extraversion, Childhood Trauma and Family Environment as Predictors of Happiness and WellBeing among Maltese University Students. Advances in Psychology Research, 65, 15-19.

[34] Galea, M. (2014) The Role of Extraversion in Predicting Burnout. In: Haddock, A. and Rutkowski, A., Eds., Psychology of Extraversion, NOVA Publishers, New York, 11.

[35] Galea, M. (2014) Modeling the Relationship between Personality and Posttraumatic Growth. In: Haddock, A. and Rutkowski, A., Eds., Psychology of Extraversion, NOVA Publishers, New York, 8.

[36] Galea, M. (2011) Healing the Healers: A Profile of Strengths and Weaknesses of Catholic Priests in Gozo, Malta. Pastoral Psychology, 60, 857-868. http://dx.doi.org/10.1007/s11089-011-0387-y

[37] Galea, M. (2012) A Conspiracy of Silence? Addressing Childhood Trauma in Malta: An Empirical Review. In: Turner, R.A. and Rogers, H.O., Eds., Child Abuse: Indicators, Psychological Impact and Prevention, NOVA Publishers, New York, 5, 85-98.

[38] Galea, M. (2012) Integrating Spirituality with Positive Psychology in View of Childhood Trauma. In: Stark, C.A. and Bonner, D.C., Eds., Handbook on Spirituality: Belief Systems, Societal Impact and Roles in Coping, NOVA Publishers, New York, 4, 85-106.

[39] Ciarrocchi, J.W. and Deneke, E. (2005) Hope, Optimism, Pessimism, and Spirituality as Predictors of Wellbeing Controlling for Personality. Research in the Social Scientific Study of Religion, 16, 161-183. 
[40] Geary, B., Ciarrocchi, J.W. and Scheers, N.J. (2004) Spirituality and Religious Variables as Predictors of Wellbeing in Sex Offenders. Research in the Social Scientific Study of Religion, 15, 167-187.

[41] Peterson, C. and Seligman, M.E.P. (2003) Character Strengths before and after September 11. Psychological Science, 14, 381-384. http://dx.doi.org/10.1111/1467-9280.24482

[42] Gorsuch, R.L. (1994) Religious Aspects of Substance Abuse and Recovery. Journal of Social Issues, 51, 65-83. http://dx.doi.org/10.1111/j.1540-4560.1995.tb01324.x

[43] Mahoney, M.J. and Graci, G.M. (1999) The Meanings and Correlates of Spirituality: Suggestions from an Exploratory Survey of Experts. Death Studies, 23, 521-528. http://dx.doi.org/10.1080/074811899200867

[44] Westgate, C.E. (1996) Spiritual Wellness and Depression. Journal of Counseling \& Development, 75, 26-35. http://dx.doi.org/10.1002/j.1556-6676.1996.tb02311.x

[45] Miller, W.R. and Thoresen, C.E. (1999) Spirituality and Health. In: Miller, W.R., Ed., Integrating Spirituality into Treatment, American Psychological Association, Washington DC, 3-18. http://dx.doi.org/10.1037/10327-001

[46] Donahue, M.J. (1985) Intrinsic and Extrinsic Religiousness: Review and Meta-Analysis. Journal of Personality and Social Psychology, 48, 400-419. http://dx.doi.org/10.1037/0022-3514.48.2.400

[47] Kane, D., Cheston, S.E. and Greer, J. (1993) Perceptions of God by Survivors of Childhood Sexual Abuse: An Exploratory Study in an under Researched Area. Journal of Psychology and Theology, 21, 228-237.

[48] Murphy, P.E., Ciarrocchi, J.W., Piedmont, R.L., Cheston, S., Peyrot, M. and Fitchett, G. (2000) The Relation of Religious Belief and Practices, Depression, and Hopelessness in Persons with Clinical Depression. Journal of Consulting and Clinical Psychology, 68, 1102-1106. http://dx.doi.org/10.1037/0022-006X.68.6.1102

[49] Galea, M. (2014) The Progressive Impact of Burnout on Maltese Nurses. SOP Transactions on Psychology, 1, 1-12. http://dx.doi.org/10.15764/STP.2014.01001

[50] Galea, M. (2014) Assessing the Incremental Validity of Spirituality in Predicting Nurses' Burnout. Archive for the Psychology of Religion, 36, 118-136. http://dx.doi.org/10.1163/15736121-12341276 